International Journal of Art and Design Education, 2005 24, 1

pp. $20-30$

\title{
Expressing the not-said: Art and design and the formation of sexual identities.
}

\author{
Nicholas Addison
}

Abstract:

Central to this paper is an analysis of the work produced by a year 10 student in response to the 'Expressive Study' of the art and design GCSE (AQA 2001). I begin by examining expressivism within art education and turn to the student's work partly to understand whether the semiconfessional mode she chose to deploy is encouraged within this tradition. The tenets of expressivism presuppose the possibility that through the practice of art young people might develop the expressive means to give 'voice' to their feelings and come to some understanding of self. I therefore look at the way she took ownership of the 'expressive' imperative of the title by choosing to explore her emerging lesbian identity and its position within the normative, binary discourses on sex and sexual identity that predominate in secondary schools. Within schooling there is an absence of formal discussion around sex, sexual identity and sexuality other than in the context of health and moral education and, to some extent, English. This is surprising given the emphasis on self-exploration that an art and design expressive study would seem to invite. In order to consider the student's actions as a situated practice I examine the social and cultural contexts in which she was studying. With reference to visual semiotics and the theoretical work of Judith Butler, I interpret the way she uses visual resources not only to represent her emerging sexual identity but to counter dominant discourses around homosexuality in schools. I claim that through her art practice she enacts the 'name of the law' to refute the binary oppositions that underpin sex education in schools. This act questions the assumptions about the purpose of expressive activities in art education with its psychologically inflected rhetoric of growth and selfhood and offers a mode of expressive practice that is more socially engaged and communicative.

Expressivism

When people express something they are said to take from within themselves some phenomenon, a sensation, perception, thought or feeling and put it outside; they take what was once inside and, through a process of transformation, represent it as a material act or thing. Such a process makes it clear that the inner something and the expression are not one and the same. However, this way of explaining the process presupposes that the inner something is prior to its expression, a common sense attitude that pervades teaching in schools. And yet, as Hal Foster argues, quoting from Nietzsche's The Will to Power III:

"The whole notion of an "inner experience" enters our consciousness only after it has found a language that the individual understands - i.e., a translation of a situation into a familiar situation ...'. This 'translation' precedes, indeed constitutes any formed expression so that between it and the self a rhetorical figure intervenes. ${ }^{1}$

In other words the inner thing is not a thing until it has been understood through the process of representation, a process that is culturally and historically coded. For humans, acts of expression are therefore not primarily emanations of an indivisible self, rather they are ways of coming to know and understand the world and ways of communicating that understanding. It is true that in 
the case of a simple reaction to external stimuli the resulting expression may be an almost involuntary sound or gesture but, more usually, expressive forms are understood as intentional acts informing others of some thing that might otherwise remain hidden. In this sense expressions are motivated signs made to produce social effects. Nevertheless, it is the inner quality that is often stressed, so much so that expression is often differentiated from other types of communication such as description or narration because it is associated exclusively with the maker's subjectivity, their inner world. Many people understand this world as something originating entirely from within the self even though subjectivity is theorised as a phenomenon formed by the social interactions of people's historical and cultural condition, what Bourdieu calls a 'habitus'. ${ }^{2}$ The common understanding however, remains a key notion in modernist theories of art and design education from Roger Fry through Herbert Read to Elliot Eisner. ${ }^{3}$

This inner-self is thus central to practice in art and design and teachers have long prided themselves on their ability to enable students to express themselves in ways denied within the logocentric curriculum with its emphasis on reason, analysis and objectivity. In particular it is argued that making art enables young people to acknowledge the affective or emotional potential of human experience. As such, students are encouraged to represent not only what is deemed good and worth remembering within a culture but also the uncertainties of experience, both conscious and unconscious fears and desires. The expressivism of art and design is therefore manifest most trenchantly in the concept of self-expression ${ }^{4}$ and students are encouraged to explore self by making art that expresses their feelings and identities. This idea, that feelings can be transformed into sensible form, is intimately bound to early modernist aesthetics. Drawing on the philosophical discussion of art since and including Immanuel Kant, Paul Crowther for example defines the work of art as a 'symbolically significant sensuous manifold', where 'we have a concrete particular which is charged with semantic and conceptual energy. It is this integral fusion of the sensuous and the conceptual which enables art to express something of the depth and richness of body-hold [embodiment] in a way that eludes modes of abstract thought such as philosophy. 5 The artist is thus able to bridge the mind/body dichotomy of Cartesian science and the alienating abstraction of language and other prescriptive systems of representation by forming something that is both concept and matter, an indivisible expression that is analogous to the mind/body symbiosis of human experience. Marsha Meskimmon expresses this concisely and eloquently: 'the work of art is the work of embodiment, of bringing us to our senses in cognition'. ${ }^{6}$ Although drawing on and responding to cultural conventions as a resource and as a challenge (both from within visual and but also other modal traditions) the modernist artist is supposed to transform the conventions of representation by exploring the potential of the concept/matter relationship. On the one hand, modernist mythology would have it that the work done by artists is the production of something unique, something formed through a very specific dialogue between the will of the artist and the limits of the material, a dialogue determined by the artists' own, not others', experience. On the other hand, in contemporary understandings of the work done with art it is recognised that this dialogue is extended through the process of reception, that is the work done by audiences in forming meanings through discussion and other discourses. As will be shown, it is the extension of the concept of expression into this later discursive domain that was to interest the GCSE student central to this paper.

\section{Selfhood}

In his analysis of art history and its relationship to the practice of artists Donald Preziosi discusses the relationship between the individual voice of the modern artist and its collective function:

From its beginnings art history was a site for the production and performance of regnant ideology, one of the workshops in which the idea of the folk and of the nation state was manufactured. Today, the extension of its disciplinary horizons to all places and times 
essentially continues this program of identifying, manufacturing, and sustaining Selfhood and solidarity. ${ }^{8}$

I would contend that in schools today the subject art and design holds on to its position within the curriculum because it promises the possibility of developing such selfhood through acts of creativity, a prize that signifies freedom within the discourse of democratic schooling. School teachers and students of art and design continue to espouse a rhetoric of creativity, individuality and selfhood despite the regularity of students' work, both in terms of orthodox processes and outcomes, and despite the attempts by anthropologists, sociologists, critical theorists and social art historians to explain the practice of artists as social processes conditioned by historical and cultural determinants rather than as isolated acts of creativity. However, the mythology of modernism sustains the view that artists are able to transcend the contexts in which they live to produce work that is both meaningful and autonomous. This unique individuality is revealed through a process of self-exploration, in which the novitiate discovers and unfolds their true essence. As Jean Dubuffet claimed in 1948:

We engage in an artistic enterprise that is completely pure, basic; totally guided in all its phases solely by the creator's own impulses. It is therefore, an art which only manifests invention, not the characteristics of cultural art which are those of the chameleon and the monkey. ${ }^{9}$

In schools, artists noted for the originality of their work are promoted, transcribed and pastiched as a means to inculcate a modernist canon that has the effect of reinforcing the myths of selfhood and expression that the art curriculum serves to perpetuate within the larger equation of reproductive schooling. It is believed that the sympathetic art teacher can provide a space in which the 'true' self of any receptive student can gradually unfold. For teachers who subscribe to the tenets of expressivism the student comes to art to express her or himself as a 'natural' rather than a 'cultural' being; the mediation of language or the imposition of codes or exemplars interferes with the free transmission of 'feeling'. It follows that within this belief system the teacher's role is to enable students to understand and embody their emotions through natural capabilities, aptitudes or talent. The fact that such embodiments are representations produced by means of a given medium, itself culturally rooted, is rarely considered in the equation. The artistry is not the manipulation of physical materials but the pure individuality of the creator: 'Expression, then, is an activity of which there can be no technique... Every utterance and every gesture that each one of us makes is a work of art'. ${ }^{10}$ Because the emphasis is on self-expression (getting it out) rather than communication (getting it across) it does not matter, in a sense, that this process is merely one of transmission. Within this theory the natural feeling, only incidentally channelled through a naturalised medium, is transmitted to the viewer as a seamless and unmediated process. All that the teacher need do is provide students with time, facilities, praise and, occasionally, technical advice (see Dick Field for an early critique of this position ${ }^{11}$ ). Many problems arise from this contention in theory, none more so than the rejection of artifice, the break with tradition and the lack of imaginative transformation that it presupposes. As Gordon Graham notes: 'It is not merely that expressivism ignores the value of imagination; it actually eliminates it. An emotion that is imagined need not be felt, and the absence of feeling is a mark of real artistic creativity'. ${ }^{12}$

As will become clear, the work of the GCSE student in question demonstrates that she was not immune to the expectations implicit within the module title, 'expressive study'. But before examining her work as an instance of the way students are able to navigate the dichotomies of expression, particularly being true to self within the context of normative schemes of assessment, it is important to indicate something of the social and cultural context of her schooling. 
School values

Rachel (a pseudonym) produced the work presented in this paper (figures $1,4,5$ ) while attending a co-educational, selective, predominantly white, middle class school. The 'liberal humanist' culture that it promotes presupposes a legitimate space for an exploration of 'self', in other words self-investigation is permissible, even encouraged. Additionally, and more pertinently, an exploration of sexual identity is possible in the art and design department because it is headed by an 'out' gay man. I realise that the particular conditions of the school and its art department are atypical and are thus not readily replicable in other schools. Nonetheless, the reproductive, normalising and regulative regimes of many comprehensive schools militate against the investigative culture that this equally reproductive but academic and elitist school inculcates because it valorises critical argument.

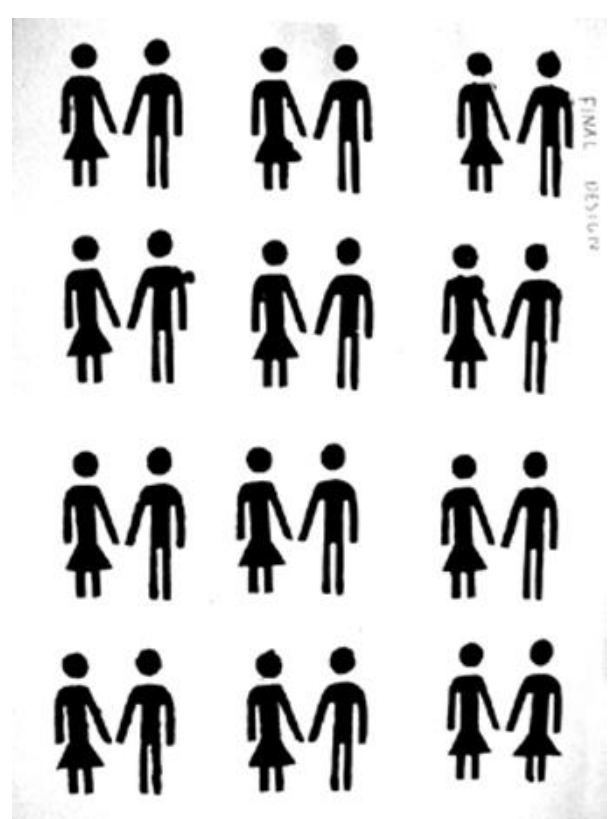

Figure 1 design for final piece

Figure 1 reproduces a page from Rachel's workbook where she resolves the design for her final artwork. All subsequent references to her work are drawn from this same source. At times I quote from her writing, on other occasions my analysis of her actions and the motivations for them are arrived at through interpretation. It is important to note that in general there is little attempt in academic research to interpret the artwork of adolescent students on its own terms, an absence that is not the case with research on children's visual production (up to and including year 7). ${ }^{13}$ The production of adolescents tends to be used to exemplify good practice within the genres of school art, or may become the focus of descriptions that reinforce the particular educational philosophies of the author. ${ }^{14}$

Initial response

In line with the expectations implicit with an 'expressive study' Rachel's initial response was to complete a series of exercises in which she explored the technical properties of a range of graphic materials in a loose, pseudo-experimental manner. In general, such exercises are encouraged to involve students in the anti-academic strategies of modernist painters, perhaps in the hope that through them they will develop forms directly indexical of the self, a process somewhat akin to 
Dubuffet's 'pure invention'. However, for Rachel such selfhood did not emerge and she transferred her efforts to pastiche, that other mainstay of preparatory work, and dutifully looked at and imitated exemplary expressionists, Pollock and Bacon, trusting that through transcription and emulation signs of the expressive would accrue to her work. However, Rachel appeared to have understood quickly that in order to express her sense of self, specifically what it feels like to be a person whose sexual orientation falls outside the social norm, the most pressing difficulties are not the result of how a young gay person feels about themselves, rather they revolve around how they are perceived and understood by others. ${ }^{15}$ As such Rachel was determined to express herself not as a unique individual but as a social being interacting with others within a heteronormative culture. To understand Rachel's motivation and representational choices it is essential to understand her expressive act in the context of discourses on sexuality in schools and sexuality and gender within art education.

Speaking of sexualities

Most research into school art education pretends to 'neutrality', in other words researchers avoid the patriarchal and masculinist discourse of modernist art education by posing as gender blind. This is just one reason why Pen Dalton's recent The Gendering of Art Education ${ }^{16}$ is a necessary and welcome counter to a stolidly patriarchal legacy. However, it is issues of gender rather than sexuality that dominate Dalton's thesis so that the ways heteronormativity reinforces and makes possible the perpetuation of patriarchy is largely unspoken. In this way she too neglects what Judith Butler refers to as 'a pervasive heterosexual assumption in feminist literary theory', namely:

those views that made presumptions about the limits and propriety of gender and restricted the meaning of gender to received notions of masculinity and femininity. It was and remains my view that any feminist theory that restricts the meaning of gender in the presuppositions of its own practice sets up exclusionary gender norms within feminism, often with homophobic consequences. ${ }^{17}$

It is heterosexuality, not homosexuality, that is the great unspoken of the curriculum, the naturalised concept in relation to which all other sexualities are 'known' and named. ${ }^{18}$ Consequently, within the binary frameworks of modernist schooling, heterosexism claims homosexuality as the practice that exists in opposition to the given reproductive norm that requires no name, the 'natural relations of sex'. Thus in the social/health curriculum it is reproductive sex, not heterosexuality, that is the named norm and it is within this context that homosexuality tends to be spoken of, objectified, and/or pathologised, spoken of with fear. In the demotic context of the 'playground' it is often the homophobic derivatives 'fag', 'lesbo', 'poof', etc. that are voiced and these terms are thrown about indiscriminately as generic markers of abuse (Haywood and Mac an Ghaill 2003: 73); any positive discourse is entirely absent:

For gay students this silence, reflecting that in wider society, pervades the whole of the curriculum, serving to reproduce and legitimate dominant heterosexual hierarchies. From this perspective, heterosexuality is presented as natural, normal and universal, simply because there are no alternative ways of being. Gay students emphasize the personal isolation, confusion, marginalization and alienation that this engenders. ${ }^{19}$

Here, the authors too easily posit a simple binary opposition to mask a complex network of power relations and thereby fail to see what others see. In wider society there is a proliferation of discourses around sexuality, including homosexuality, ${ }^{20}$ and it is within these discourses that nonprocreative sexualities take on their relative position within a hierarchy of legitimacy. For example, at the close of the twentieth century the complete invisibility of lesbian artists within 
popular stories of modern art was particularly noticeable, as Harmony Hammond asserted in 1978:

The silence, the words omitted from the biographies of lesbian artists, have denied us role models and the possibility of developing work that acknowledges lesbian experience as a creative source for art making and a context in which to explore it. I refuse to let them dispose of me in this way - to obliterate my existence as a lesbian and as an artist. I refuse to be quiet; I want lesbian artists to be visible. ${ }^{21}$

With her recent Lesbian Art in America: A Contemporary History ${ }^{22}$ Hammond herself has begun to redress this absence, but her publication is a contribution to, or intervention within, a discourse that rarely enters schooling in the UK.

I do not wish to diminish the sense of isolation that many gay and lesbian students and teachers may experience in schools; in this, as in many other instances, what is not said in school is not what is not said in wider society. Within discourses on sexuality and sex the tenor of any dialogue in which homosexuality is mentioned depends on when and where dialogue takes place, who speaks and with whom, and the operative and performed power relations of the participants. $^{23}$

In Rachel's school, where academic achievement is the expected norm, the homophobic insults that male academic achievers receive in many schools are inappropriate epithets (although 'gay' is sometimes used to indicate 'trashy', weak, of little significance). Indeed, a homosexual 'disposition' (camping it up) may be selected and paraded by the male dissident/alienated student as a counter-identity, even in the absence of same-sex sexual desire/practice; a ready-made with which to assert difference and/or resistance to institutional hegemony. However, within the homosocial spaces of co-educational schooling, intimate, even physical relations are permissible for girls; they can hold hands, embrace and perform in such ways that are only permissible to boys in the arena of sports. In this sense it might be possible for developing lesbian relationships to be partially hidden, although research indicates that other barriers intervene. ${ }^{24}$ Within the expressive practices of art and design it might be supposed that such barriers could be eroded freeing students to examine sexuality in the metaphoric spaces that traditions of visual art provide. Indeed, in the context of an expressive module, any investigation of the early twentieth century Expressionists would have unearthed sexuality as a primary concern for artists who were questioning the consolidation of bourgeois morality. ${ }^{25}$

Selecting resources for personal expression

The sequence of images in Rachel's workbook indicates that despite the absence of positive lesbian imagery in school she was not going to go down the obvious path of expressing feelings of frustration. Rather she decided to produce an image that would force viewers to confront their own feelings on the matter. She therefore decided to examine the stigmatisation of same sex couples by inserting their presence into the signage system denoting the binary male/female (figure. 2). 


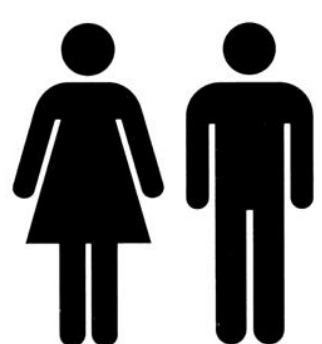

Figure 2

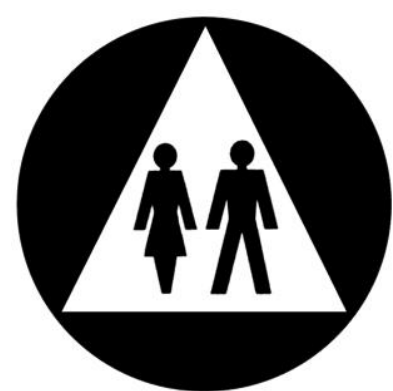

Figure 3

Rachel's choice of an increasingly global system with its regularity and repeatability is perhaps surprising for a module that tends to encourage a looser, more gestural manner. This 'free' way of handling materials has come to signify as a marker of expressivity denoting, ironically, the conventions of the non-conventional: authenticity, originality and spontaneity. Rachel's unexpected choice has encouraged me to look at her work in order to analyse the emergent process of meaning making central to the expressive impulse rather than focus on the qualitative features of the representation itself, the final product so often foregrounded in assessment of expression. In my analysis I use the terms male/female to indicate the biological category common to all sexed life forms, although the terms man/woman are often used synonymously with male/female. Here I wish to acknowledge them as gendered categories indicating behaviours and practices that are historically and culturally determined and performed as signs of the masculine/feminine opposition. The common conflation of these terms indicates the naturalised status afforded systems of gender representations, despite their cultural codification rather than biological status. ${ }^{26}$ I use the terms 'icon', 'index' and 'symbol' as categories derived from Charles Sanders Peirce to denote the different ways in which visual signs refer to objects or ideas, respectively through similarity, causal relationship or through a rule. ${ }^{27}$

The triangular shape on the one figure iconically represents a skirt (figure 2), a type of garment that in the west is worn by women and girls to locate them within the symbolic space designated female. The way this signage system has proliferated in public spaces demonstrates subtle but marked variations (figure 3). In many instances, the legs of the female sign are so close together that it is impossible for any light to escape from between them. Alternatively, in fewer but significant numbers, the legs are ever so slightly apart. In relation to the male sign this parting is somewhat 'demure' for his gait is fully astride, a sort of necessary swagger. These differences signify the distinct body postures deemed appropriate for men and women and demonstrate the constraints on women's bodies, patriarchy's introjected regulation: 'It is through the body too, that women in our culture learn their own particular form of self-surveillance... The discursive practices which produce femininity are in the culture and within women. Thus they diet, dress for certain effect, monitor their movement and gestures' ${ }^{28}$ Nonetheless, there is one index of sex, of a supposed biological or physiological difference, the male's shoulders are square the female's round (and in others, the male's are broader). But this 'biological' signifier cannot be applied universally, such denotation could be achieved more convincingly, for example, by providing one of two identically shaped heads with full, facial hair. These figure signs are particularly ubiquitous when indicating segregation in public toilets; only the status of disability or infancy allows the user to transgress the division, although in the former case a separate unisex unit is provided. Identification by the user with one or other representation provides them with a symbol for entry or non-entry and thus ensures segregation. But there is no clear evidence in Rachel's workbook to suggest that these issues were consciously on her mind as she made her choices (although it is significant that the only difference in her couple is the triangle). With reference to her preparatory work I aim to retrace the development of her thinking. 
Coming out through art practice

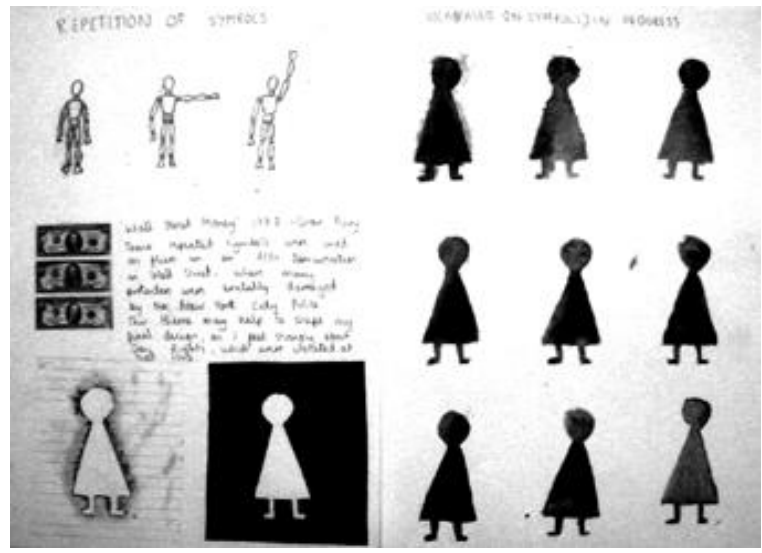

Figure 4

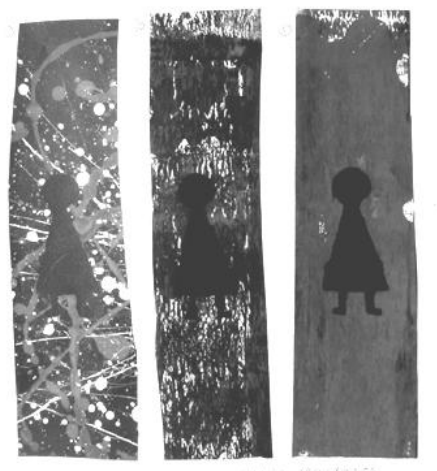

Figure 5

Initially Rachel was determined to signify the isolation and difference of the queer position. Unlike the fully-limbed counterpart in the global signage, her female sign, what she called a 'symbol' (figure 4) is all head and dress, only diminutive legs transform what registers as a selfasserting keyhole towards a would-be-human; in effect this armless cypher signifies a lack. With the proliferation of this cypher (right hand page figure 4) Rachel indicated the female domain as a regulated field made up from a duplicating and grid-bound sign. This grid is contrasted on the previous page by three other sets of image: one, an artist's mannequin whose left arm is suddenly animated; two, a set of dollar bank notes (appropriated for the anti-capitalist AIDS demonstration in Wall Street 1988); three, the cypher prototype and stencil. Here the layout of the images and the sequence of their making follows the conventions of printed text. so that reading from the top, left to right, the mannequin coming to life is the starting point. Following the theories of Kress and Leeuwen ${ }^{29}$ this entry point is the domain of the given and thus represents the male-orientated conventions of expressivism. With this beginning, and the juxtaposition of the two pages, the seemingly gender-neutral mannequin is designated male. The contrast between this animated man and armless girl indicates the lack of agency, the forced passivity of the female role within patriarchy. The appropriation of dollar bills by gays (acknowledged in the text to their right) is at once a recognition of the power of patriarchy but also of the possibility of resistance. But the red colour and marginal position of the queer girl (bottom right) further segregate and make visible her difference within a heteronormative matrix. Rachel tried out her figure on a series of undifferentiated backgrounds (both pastiches of notable expressionist/outsider artists and experiments with ink and roller: figure 5) but decided that this isolation, indeed almost a desolation, did not confirm the social and interactive message that she hoped to communicate. This isolation proved intolerable for her because it represented a form of non-recognition; in contradistinction, by representing a lesbian couple among heterosexual couples she attained 'a 
certain order of social existence, in being transferred from an outer region of indifferent, questionable, or impossible being to the discursive or social domain of the subject' ${ }^{30}$

Through this choice Rachel began to represent her move towards agency and, thus empowered, also considered the inclusion of other forms of prejudice, specifically racism and ablism. However, she eventually decided to stay with the autobiographical concerns typical of an expressive study and her attentions refocused on gendered signage systems and grids. As her drawings developed the grid lost its female singularity and was filled up with heterosexual couples, the binary given of the patriarchal family. She explicated her thinking in her work book:

In my piece I hope to provoke people's unconscious opinions and thoughts. I will do this by using symbolism. Previously in my book, I have used (and chosen for my final design) the symbolism of couples. My designs have been showing how certain people stand out, and I have shown through colour, e.g. colouring them red, and everything else black.

However, if I was to paint all my symbols the same colour, people would have to use their minds more to work out the message. All my symbols will be of a boy and girl holding hands, except for one, which will show two girls holding hands. The significance of all the symbols being the same colour would be far bigger than if one stood out. This is because by making them all the same colour I am showing that the two girls are no different from the other couples, and hopefully those viewing my work will see this. It will lead people to think whether they do have inner prejudices when they realize there is a lesbian couple in my piece, and this may show them that having these prejudices inside them is unnecessary, and they are only there to comply with out dated conventions. $^{31}$

For her final design (figure 1), in choosing black rather than red as the colour for the same-sex couple, Rachel indicated her desire for integration, for a normalisation of lesbian relationships to the point where they may be overlooked. In this way she hoped for acceptance within the symbolic order, her graphic expression was not one of assertive difference but of negation, a saying no to exclusion; the final piece stands as a mature and rational response to a perceived injustice. In this sense Rachel engaged fully with that order and she did so by refusing the possibility of a fully differentiated identity, she rejected the possibility of a separate, concrete signifier produced through an exploration of material differences, the concept/matter dialogue of modernist practice.

Despite the ethical basis of Rachel's resistance, her utopian dream (the self-enlightenment of bigots) is however more likely to result in a confirmation of heteronormative beliefs. In her workbook she positioned herself within a genealogy of gay artists who have been subject to public censure, from Bacon to Gilbert and George but also within a continuum of feminist practice citing Barbara Kruger and Rebecca Horn. In this affiliation she recognised the necessity for work that is less traditionally expressive and more overtly political. But for this module she decided to engage with a discursive field of practice rather than explore the possibility of expression without language, a 'concretisation of queer experience'. In this way her final piece is both resistant and confessional.

Conclusion

However, in Rachel's act the sin is thrown back at the confessor; difference is minimised so that if and when viewers notice difference, the pleasure or distaste they feel exposes their responses as phobic or philic bringing them face to face with their prejudices. Within the heteronormative 
matrix of school morality Rachel might have expected censure or sanction, but she codified her resistance in such invisible terms that her final design mimics the law itself. To appropriate Butler's explanation of transgressive resistance Rachel's work might:

be understood as repetitious of hegemonic forms of power which fail to repeat loyally and, in that failure, open up possibilities for resignifying the terms of violation against their violating aims... the reworking of 'queer' from abjection to politicized affiliation will interrogate similar sites of ambivalence produced at the limits of discursive legitimacy. $^{32}$

Rachel's situated acts are undoubtedly an instance of the way the metaphoric spaces of art and design allow students to engage with personal issues of sexuality in a way that the more usual pedagogic discourses, biological, medical and moral, may inhibit. But she moved beyond the usual limitations of expression within the traditions of school art (where students attempt to express an aspect of their indivisible selves) to a consideration of how audiences might react to a subtle provocation, a social, interpersonal space in which expressions are mooted and shared. Art and design as a disjunction, a sort of 'other' within the logocentric curriculum, is able to upset the expected symbolic force of pedagogic power relations to challenge the normalising function of schooling and provide a space for difference. Perhaps in art and design (and the other school subjects consciously concerned with cultural production) the school student can be recognised as an experiential, desiring, wilful, pleasure-seeking, intersubjective being, a person capable of negotiating an identity that is both personally affirming and socially enabling, but also a space where refusal has a legitimate place and where identities do not have to be fixed within essentialist tags.

\footnotetext{
References

${ }^{1}$ Foster, H. (1985) ‘The Expressive Fallacy’ In Recodings Port Townsend Wash: Bay Press. p.62

${ }^{2}$ Bourdieu, P. (1993) 'Field of Power, Literary Field and Habitus'. In: The Field of Cultural Reproduction. Cambridge: Polity Press.

${ }^{3}$ Fry, R. (1909) 'An Essay in Aesthetics.' In: F. Frascina. and C. Harrison (eds) (1982) Art and Modernism. London: Paul Chapman in association with the Open University; Read, H (1943) Education Through Art. London: Faber and Faber; Eisner, E. (1972) Educating Artistic Vision. New York: Macmillan.

${ }^{4}$ Atkinson, D. (2002) Art in Education: Identity and Practice. Dordrecht, Boston, London: Kluwer Academic Publishers. P. p.138

${ }^{5}$ Crowther, P. (1993) Art and Embodiment. Oxford: Clarendon Press. p. 5

${ }^{6}$ Meskimmon, M. (2003) Women Making Art. London: Routledge. p.5

${ }^{7}$ Bal, M. and Bryson, N. (1991), 'Semiotics and Art History: A Discussion of Context and Senders.' In: D. Preziosi (ed.) (1998) The Art of Art History; A Critical Anthology. Oxford: Oxford University Press.

${ }^{8}$ Preziosi, D. (1989) Rethinking Art History. New Haven and London: Yale University Press. p. 33
} 
${ }^{9}$ Dubuffet, J. (1948) ‘Crude Art Preferred to Cultural Art' In: C. Harrison, and P. Wood. (eds) (1992) Art in Theory 1900 - 1990. Oxford: Blackwell. p. 595

${ }^{10}$ Collingwood, R. G. (1938) The Principles of Art. Oxford: Oxford University Press. (Collingwood in Ridley 2003).

${ }^{11}$ Field, D. (1970) Change in Art Education. New York: Routledge and Kegan Paul and Humanities Press.

${ }^{12}$ Graham, G. (1997) Philosophy of the Arts: An Introduction to Aesthetics. London: Routledge. p. 29

${ }^{13}$ For recent examples see Atkinson, D. op. cit and Matthews, J. (1999) The Art of Childhood and adolescence: The Construction of Meaning. London: Falmer Press. In the latter only one chapter of 14 pages is dedicated to the work of an adolescent, and he is 'atypical'.

${ }^{14}$ Taylor, R. (1986) Educating for Art. Burnt Mill: Longman.

${ }^{15}$ Cameron, D. and Kulick, D. (2003) Language and Sexuality. Cambridge: Cambridge University Press.

${ }^{16}$ Dalton, P. (2001) The Gendering of Art Education. Buckingham: Open University Press.

${ }^{17}$ Butler, J. (1999) Gender Trouble: Feminism and the Subversion of Identity. New York and London: Routledge.

${ }^{18}$ Epstein, D. and Johnson, R. (1994) ' in D. Epstein (ed.) Challenging Lesbian and Gay Inequalities in Education. Buckingham: Open University Press.

${ }^{19}$ Haywood, C. and Mac an Ghaill, M. (2003) Men and Masculinities. Buckingham: Open University Press. p. 78

${ }^{20}$ Epstein, D. and Johnson, R. (1998) Schooling Sexualities. Buckingham: Open University Press. p. 202

${ }^{21}$ Hammond, H. (2003) 'Lesbian Artists' in A. Jones (ed.) The Feminism and Visual Culture Reader. London and New York: Routledge. p. 129

${ }^{22}$ Hammond, H. (2000) Lesbian Art in America: A Contemporary History

${ }^{23}$ Foucault, M. (1998) The Will to Knowledge: The History of Sexuality: 1. Harmondsworth: Penguin.

${ }^{24}$ Epstein, D. and Johnson, R. op. cit

${ }^{25}$ Rowe, D. (2003) Representing Berlin: Sexuality and the City in Imperial and Weimar Germany. Burlington, VT: Ashgate.

${ }^{26}$ Cameron, D. and Kulick. D. op. cit.

${ }^{27}$ Peirce, C. S. (1966) Selected Writings: Values in a Universe of Chance. New York: Dover.

${ }^{28}$ Wolff, J. (2003) 'Reinstating Corporeality', in A. Jones (ed.) The Feminism and Visual Culture Reader. London and New York: Routledge. p. 417

${ }^{29}$ Kress, G. and Leeuwen, T. (1996) Reading Images: The Grammar of Visual Design. London: Routledge. 
${ }^{30}$ Butler, J. (1998) ‘Gender Is Burning: Questions of appropriation and subversion’ In N. Mirzoeff (ed.) The Visual Culture Reader. London and New York: Routledge. p. 449

${ }^{31}$ Anon. (2001) GCSE Expressive study, module workbook. London.

${ }^{32}$ Butler, J. (1998) op.cit. p. 450 